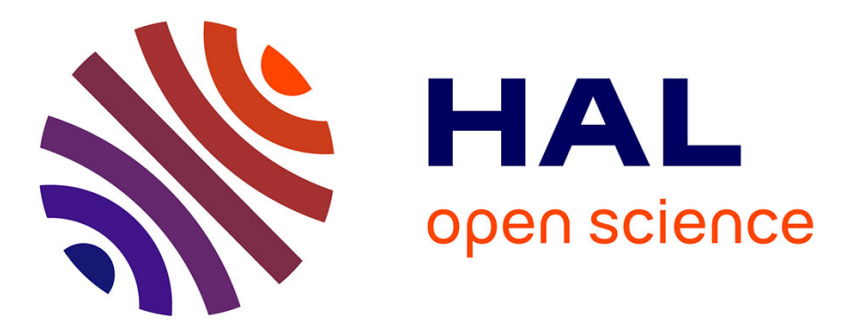

\title{
Note complémentaire sur l'identité du commanditaire du mausolée
}

\author{
Henri Lavagne
}

\section{To cite this version:}

Henri Lavagne. Note complémentaire sur l'identité du commanditaire du mausolée. Gallia - Fouilles et monuments archéologiques en France métropolitaine, 1990, Le mausolée de Cucuron (Vaucluse), 47, pp.202. 10.3406/galia.1990.3162 . hal-02477695

\section{HAL Id: hal-02477695 https://hal.science/hal-02477695}

Submitted on 13 Feb 2020

HAL is a multi-disciplinary open access archive for the deposit and dissemination of scientific research documents, whether they are published or not. The documents may come from teaching and research institutions in France or abroad, or from public or private research centers.
L'archive ouverte pluridisciplinaire HAL, est destinée au dépôt et à la diffusion de documents scientifiques de niveau recherche, publiés ou non, émanant des établissements d'enseignement et de recherche français ou étrangers, des laboratoires publics ou privés.

\section{(이) $\$$}

Distributed under a Creative Commons Attribution - NonCommercial - NoDerivatives| 4.0 


\section{NOTE COMPLÉMENTAIRE SUR L'IDENTITÉ DU COMMANDITAIRE DU MAUSOLÉE}

Nous voudrions faire état ici d'une hypothèse que J. Gascou, au cours de ses recherches sur les inscriptions de Cucuron, nous avait d'abord proposée, mais qu'avec sa prudence d'épigraphiste, il avait préféré ne pas retenir à cause d'incertitudes de lecture. Elle consistait à adopter un rapprochement d'O. Hirschfeld ${ }^{15}$, entre une inscription trouvée à Aix-en-Provence, mentionnant une famille de notables locaux dont deux représentants sont les frères C. Aemilius Vastus et T. Aemilius Burrus et, d'autre part, une inscription aujourd'hui perdue, mais mise au jour à Cucuron même, au Xvi $\mathbf{r}^{\mathrm{e}} \mathrm{s}$. et connue par un manuscrit de l'érudit aixois, Jules Raymond de Solier ${ }^{16}$. Celle-ci porte également les noms de C. Aemilius et de T. Aemilius, sans cognomina, mais avec l'indication VIVIR accompagnant le nom de C. Aemilius. Hirschfeld suggérait de voir dans ces deux inscriptions une seule et même pierre concernant les deux mêmes personnages; la pierre de Cucuron aurait été mutilée puis amenée à Aix-enProvence. A juste titre, J. Gascou refuse cette hypothèse puisque les textes de ces deux inscriptions ne se confondent que très partiellement. Il suggère donc, pour sa part, qu'il y a eu mauvaise lecture de J.R. de Solier et propose de lire: T. Aemilius et C. Aemilius VIVI P(osuerunt) SVIS, et non pas: VIVIR SVIS. Les deux frères de Cucuron ne seraient pas ceux d'Aix-en-Provence et auraient "de leur vivant, élevé (ce monument) pour les leurs». Mais en examinant avec soin le manuscrit de Solier, nous avons pu constater que la lecture VIVIR est incontestable, avec une barre oblique du $R$ très

15 CIL XII, 1113, commentaire d'Hirschfeld à l'inscription de Cucuron et son rapprochement avec l'inscription CIL XII, 537, d'Aix-en-Provence.

16 Jules Raymond de Solier (date de naissance inconnue, mort entre 1589 et 1593). Le manuscrit comportant l'inscription de Cucuron est intitulé Rerum antiquarum et nobiliorum Provinciae commentarii et est conservé à la Bibliothèque Méjanes d'Aix-en-Provence (ms. 797, p. 143). Sur cet érudit, voir A. HÉron de VILlefosse, H. ThÉdENAT, Inscriptions romaines de Frëjus, Tours-Paris, 1884, p. 174-184 et J. Anglade, Extraits de la vie de J. R. de Solier par J. de Haitze, Annales du Midi, 24, 1912, p. 535-551. développée; comme il est courant de le voir sur les inscriptions du début de l'Empire. Ajoutons que Solier est un grand lecteur d'inscriptions antiques, un collectionneur et l'un des meilleurs érudits de son temps; en outre, pendant les troubles des guerres de Religion, il a vécu à Pertuis qui n'est qu'à $12 \mathrm{~km}$ de Cucuron. Il a donc très probablement vu lui-même la pierre et sa transcription est digne de foi. C'est pourquoi nous inclinons à faire de $C$. Aemilius, le sévir nommé à Cucuron, le même personnage que celui qui apparait dans l'inscription aixoise, même s'il ne s'agit pas d'une seule pierre comme le voulait Hirschfeld. L'absence de cognomen à Cucuron n'est pas un argument absolument dirimant puisqu'on sait qu'au $\mathrm{I}^{\mathrm{er}} \mathrm{s}$, l'onomastique pratique souvent les dénominations courtes, comme l'exemple du mausolée des Julii nous l'apprenait déjà pour une période antérieure, le fait étant encore bien attesté pendant les premières décennies de l'Empire ${ }^{17}$. Comme le remarquait $\mathbf{J}$. Gascou, l'origine de la famille est, en tout cas, probablement gauloise et la citoyenneté a pu être accordée à un ancêtre de $C$. Aemilius par $M$. Aemilius Lepidus, qui fut gouverneur de Transalpine de 44 à 42 avant J.-C. Nous aurions ainsi un nouvel exemple de ces notables aixois qui font carrière à la ville, mais se font inhumer dans le mausolée familial de leur maison de campagne dans l'arrière-pays de la Durance. C'était déjà le cas pour les Domilii du mausolée de Rognes.

\section{Henri Lavagne}

17 Cf. P. Gros, Le mausolée des Julii et le statut de Glanum, Revue Archéologique, I, 1986, p. 75, note 48.

\section{Nota Bene}

L'illustration de cet article est due à MM. J. Lenne (fig. 1, 16, 19), A. Chéné, Institut d'études méditerranéennes, CNRS (fig. 3), R. Guéry (fig. 4, 5, 6, 9, 15, 30, 35, 37, 41), Chr. Landes (fig. 11, 17, 20), J.-Cl. Béal (fig. 12), G. Reveillac, Centre Camille Jullian, CNRS (fig. 13, 14, 18, 24, 25, 26, 27, $42,45,47,48,52,53$ ), G. Hallier (fig. $2,7,8,10,21,22,23$, $28,29,31,32,33,34,36,38,39,40)$, Musée Calvet, Avignon (fig. 46), IAM (fig. 43 et 44). 